\title{
Stage IIA and IIB testicular seminoma treated post- orchiectomy with radiation therapy versus other approaches: a population-based analysis of 241 patients
}

\author{
Kamran A. Ahmed ${ }^{1}$, Richard B. Wilder ${ }^{1}$ \\ ${ }^{1}$ Department of Radiation Oncology, H. Lee Moffitt Cancer Center and Research Institute, Tampa, FL, USA
}

\section{ABSTRACT}

Objectives: To evaluate post-orchiectomy utilization of radiation therapy (RT) versus other management approaches in stage IIA and IIB testicular seminoma patients.

Materials and Methods: Two hundred and forty-one patients with stage IIA and IIB testicular seminoma were identified between 1988 and 2003 using the Surveillance, Epidemiology, and End Results (SEER) database.

Results: Median follow-up was 10 years. Patients with stage IIA disease underwent RT more frequently than those with stage IIB disease ( $72 \%$ vs. $46 \%$, respectively; $\mathrm{P}<0.001$ ). There was no significant change in RT utilization for stage IIA or IIB disease between 1988 and $2003(\mathrm{P}=0.89)$.

Conclusions: Between 1988 and 2003, stage IIA patients underwent RT more often than stage IIB patients in the United States. There was no significant change in RT utilization for stage IIA or IIB disease during this time period. Based on reports describing excellent progression-free survival with cisplatin-based chemotherapy, this approach has increased in popularity since 2003 and may eventually become the most popular treatment approach for both stage IIA and IIB testicular seminoma.
ARTICLE INFO

\section{Key words:}

Testicular Neoplasms; Seminoma; Radiotherapy; Antineoplastic Agents

Int Braz J Urol. 2015; 41: 78-85

Submitted for publication: October 23, 2013

Accepted after revision: May 05, 2014

\section{INTRODUCTION}

Testicular cancer is the most commonly-diagnosed malignancy in men between the ages of 20 and 45 years. The American Cancer Society estimates that there were 7,920 new cases and 370 deaths due to testicular cancer in the United States (U.S.) in 2013 (1). Eighty percent of testicular seminoma patients present with stage I disease and 11\% present with stage II disease (2).
Standard of care post-orchiectomy for stage IIA and IIB testicular seminoma is radiation therapy (RT) or cisplatin-based combination chemotherapy $(3,4)$.

Prior studies of RT for stage IIA and IIB testicular seminoma have involved fewer than 130 patients (5-8). The purpose of this study is to analyze utilization of RT vs. other management approaches for stage IIA or IIB testicular seminoma in a relatively large number of patients 
based upon an analysis of the Surveillance, Epidemiology and End Results (SEER) database.

\section{MATERIALS AND METHODS}

The SEER program created by the National Cancer Institute (NCI) includes population-based cancer registries from 20 selected geographic areas in the U.S., covering approximately $28 \%$ of the national population. Data is submitted to the NCI registry on an annual basis without "identifiable" private information, and the NCI makes the data available to the public for research purposes. As a result, this study was exempt from Institutional Review Board review. Patient data was obtained via a query of the SEER dataset (November 2012 edition). The population for this study consisted of patients diagnosed with stage IIA and stage IIB pure testicular seminoma. $\mathrm{Pa}-$ tients treated between 1988 and 2003 were identified using the following extent of disease codes for the primary tumor: T1: 10, 20, 30, and 40; T2: 15 and 45; T3: 50; and T4 60 and 70. For regional lymph nodes, extent of disease code one was used for $\mathrm{N} 1$ disease and code two was used for N2 disease. In the SEER database, patients are listed simply as having received RT or not having received RT. The database does not state the management approach that was used post-orchiectomy in patients who did not undergo RT. Also, it does not state whether a particular treatment approach (RT vs. other) was based upon physician recommendation or patient preference. In addition, RT and chemotherapy details, including dosages, are not included in the SEER database. Moreover, initial volume of nodal disease, relapse-free survival including sites of relapse, and non-lethal toxicities are not included. Patients in whom the stage grouping was unknown were excluded. Stage IIC disease was excluded because cisplatin-based combination chemotherapy for good-risk patients as defined by the International Germ Cell Cancer Collaborative Group (IGCCCG) constitutes the standard of care (9), precluding a statistical analysis of RT vs. other management approaches. There is no consensus on the definition of educational level. A low educational level was defined in this study as a high school graduation rate of $<75 \%$, a moderate educational level was defined as a high school graduation rate of $75-85 \%$, and a high educational level was defined as a high school graduation rate of $>85 \%$.

Statistical analysis was performed using SAS 9.2 and JMP 7 (SAS Institute Inc., Cary, NC). Survival analysis was carried out using Kaplan-Meier estimates. The log-rank test was used to test for differences in survival. A non-parametric test of medians was used to assess continuous variables. A P-value less than 0.05 was considered to be statistically significant. The Cox proportional hazard model was used for univariate and multivariate analyses to assess the effect of patient characteristics on outcomes.

\section{RESULTS}

\section{Patient Characteristics}

One hundred and forty-five of 241 (60\%) patients had stage IIA testicular seminoma and 96/241 (40\%) patients had stage IIB testicular seminoma in the SEER database between the years of 1988 and 2003. Patient characteristics are presented in Table-1.

\section{Stages IIA and IIB Combined}

Median follow-up was 10 years. Twenty-two of 241 (9\%) patients died. For stages IIA and IIB combined, the 5-, 10-, and 15-year overall survival (OS) rates were 95\%, 91\%, and 89\%, respectively. The 5-, 10-, and 15-year cause-specific survival (CSS) rates were 98\%, 97\%, and 97\% respectively.

\section{Stage IIA vs. IIB}

Race, age, educational level, and marital status did not correlate with patient selection for RT. Patients with T1 disease underwent RT more frequently than those with T3 disease (64\% vs. 16\%, respectively; $\mathrm{P}<0.001)$. Also, patients with stage IIA disease underwent RT more frequently than those with stage IIB disease (72\% vs. 46\%, respectively; $P<0.001)$. There was no significant change in RT utilization for stage IIA or IIB disease between 1988 and $2003(\mathrm{P}=0.89)$. Causes of death in stage IIA and IIB patients are presented in Table-2. 
Table 1 - Characteristics of Stage IIA and IIB Testicular Seminoma Patients.

\begin{tabular}{|c|c|c|c|c|c|c|c|}
\hline \multirow[b]{2}{*}{ Characteristic } & \multicolumn{2}{|c|}{$\begin{array}{l}\text { All Patients } \\
(n=241)\end{array}$} & \multicolumn{2}{|c|}{$\begin{array}{l}\text { Radiotherapy } \\
\qquad(\mathrm{n}=136)\end{array}$} & \multicolumn{2}{|c|}{$\begin{array}{l}\text { No Radiotherapy } \\
\quad(n=105)\end{array}$} & \multirow[b]{2}{*}{$P$} \\
\hline & $\mathrm{n}$ & $\%$ & $n$ & $\%$ & $\mathrm{n}$ & $\%$ & \\
\hline \multicolumn{8}{|l|}{ Age (years) } \\
\hline $18-39$ & 139 & $58 \%$ & 76 & $55 \%$ & 63 & $45 \%$ & 0.52 \\
\hline $40-76$ & 102 & $42 \%$ & 60 & $59 \%$ & 42 & $41 \%$ & \\
\hline \multicolumn{8}{|l|}{ Marital Status } \\
\hline Single & 97 & $40 \%$ & 52 & $54 \%$ & 45 & $46 \%$ & 0.59 \\
\hline Married & 125 & $52 \%$ & 75 & $60 \%$ & 50 & $40 \%$ & \\
\hline Divorced & 16 & $7 \%$ & 8 & $50 \%$ & 8 & $50 \%$ & \\
\hline Unknown & 3 & $1 \%$ & 1 & $33 \%$ & 2 & $67 \%$ & \\
\hline \multicolumn{8}{|l|}{ Race } \\
\hline White & 219 & $91 \%$ & 127 & $58 \%$ & 92 & $42 \%$ & 0.12 \\
\hline Non-White & 22 & $9 \%$ & 9 & $41 \%$ & 13 & $59 \%$ & \\
\hline \multicolumn{8}{|l|}{ Year of Diagnosis } \\
\hline $1988-1991$ & 14 & $6 \%$ & 7 & $50 \%$ & 7 & $50 \%$ & 0.89 \\
\hline $1992-1995$ & 43 & $18 \%$ & 23 & $53 \%$ & 20 & $47 \%$ & \\
\hline 1996-1999 & 52 & $22 \%$ & 31 & $60 \%$ & 21 & $40 \%$ & \\
\hline $2000-2003$ & 132 & $54 \%$ & 75 & $56 \%$ & 57 & $44 \%$ & \\
\hline Educational Level & & & & & & & 0.47 \\
\hline Low & 65 & $27 \%$ & 37 & $57 \%$ & 28 & $43 \%$ & \\
\hline Intermediate & 102 & $42 \%$ & 56 & $55 \%$ & 46 & $45 \%$ & \\
\hline High & 74 & $31 \%$ & 43 & $58 \%$ & 31 & $42 \%$ & \\
\hline \multicolumn{8}{|l|}{ Primary Tumor (T) } \\
\hline $\mathrm{T} 1$ & 150 & $62 \%$ & 96 & $64 \%$ & 54 & $36 \%$ & $<0.001$ \\
\hline $\mathrm{T} 2$ & 39 & $16 \%$ & 23 & $59 \%$ & 16 & $41 \%$ & \\
\hline T3 & 18 & $7 \%$ & 3 & $16 \%$ & 15 & $84 \%$ & \\
\hline $\mathrm{T} 4$ & 5 & $2 \%$ & 3 & $60 \%$ & 2 & $40 \%$ & \\
\hline TX & 29 & $12 \%$ & 11 & $38 \%$ & 18 & $62 \%$ & \\
\hline \multicolumn{8}{|c|}{ Regional Lymph Nodes } \\
\hline $\mathrm{N} 1^{*}$ & 96 & $40 \%$ & 69 & $72 \%$ & 27 & $28 \%$ & $<0.001$ \\
\hline $\mathrm{N} 2 \dagger$ & 145 & $60 \%$ & 67 & $46 \%$ & 78 & $54 \%$ & \\
\hline
\end{tabular}

*Stage IIA

†Stage IIB 
Table 2 - A) Causes of Death in Stage IIA Testicular Seminoma Patients, B) Causes of Death in Stage IIB Testicular Seminoma Patients.

A

\begin{tabular}{lcc}
\hline Cause of Death $(n=9)$ & Radiotherapy $(n=69)$ & No Radiotherapy $(n=27)$ \\
\hline Testicular Cancer & 2 & 2 \\
Lung Disease & 1 & 1 \\
Acute Myeloid Leukemia & 0 & 1 \\
Accident & 0 & 1 \\
Unknown & 0 & No Radiotherapy (n=78) \\
B & Radiotherapy (n=67) & 3 \\
\hline Cause of Death $(n=13)$ & 1 & 2 \\
Unknown & 1 & 1 \\
Testicular Cancer & 2 & 1 \\
Heart Disease & 1 & 1 \\
Lung Disease & 0 & 1 \\
Infection & 0 & 1 \\
Colon Cancer & & 1 \\
\hline
\end{tabular}

Patients with stage IIA disease who received RT had a 5-, 10-, and 15-year OS rate of 96\% compared with 88\%, 77\%, and 77\%, respectively, for those who underwent other management approaches $(\mathrm{P}=0.008$; Figure-1). The 5-, 10-, and 15year CSS rate for stage IIA disease was 97\% for RT compared with 96\%, 92\%, and 92\%, respectively, for other management approaches $(P=0.30)$.

Improved OS ( $\mathrm{P}=0.03$; Figure- 2$)$ was noted in patients with stage IIB disease who received RT (5-, 10-, and 15-year OS rates of 98, 96\%, and 88\%, respectively) as opposed to no RT (5-, 10-, and 15year OS rates of $90 \%, 86 \%$, and $86 \%$, respectively). The 5-, 10-, and 15-year CSS rate was 98\% for stage IIB patients who received RT compared with 98\%, 96\%, and 96\%, respectively, for those who underwent other management approaches $(\mathrm{P}=0.60)$.

\section{Univariate and Multivariate Analyses}

On univariate analysis, race, educational level, marital status, treatment year, and $\mathrm{T}$ and $\mathrm{N}$ stage were not associated with OS or CSS. Increasing age was associated with worse OS $(\mathrm{P}=0.009)$, but not CSS $(P=0.11)$. Age was associated with worse OS on multivariate analysis as well, adjusting for race, $\mathrm{T}$ and $\mathrm{N}$ stage, year of treatment, use of RT, marital status, and educational level. The use of RT correlated with improved OS (HR 0.30; 95\% CI: 0.12-0.74; $\mathrm{P}=0.008)$ but not CSS $(\mathrm{P}=0.35)$ on univariate analysis. The use of RT correlated with improved OS on multivariate analysis as well (HR 0.40; 95\% CI: 0.15-0.90; P = 0.02).

\section{DISCUSSION}

The bulk of retroperitoneal adenopathy is the most important prognostic factor in stage II disease (5). There have been no prospective, randomized trials involving stage IIA or IIB testicular seminoma due to the rarity of such patients. As a result, treatment recommendations have commonly been guided by reports from single institutions (3). 
Figure 1 - Overall survival for stage IIA testicular seminoma patients managed with radiation therapy vs. other approaches.

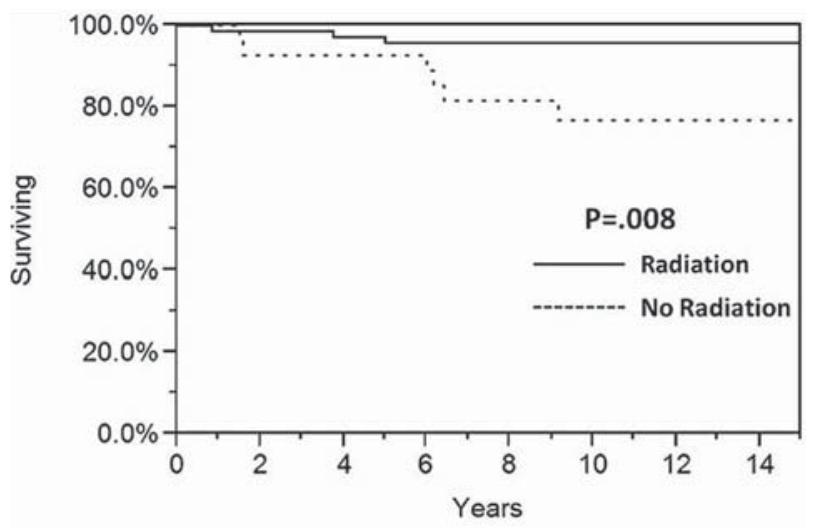

Figure 2 - Overall survival for stage IIB testicular seminoma patients managed with radiation therapy vs. other approaches.

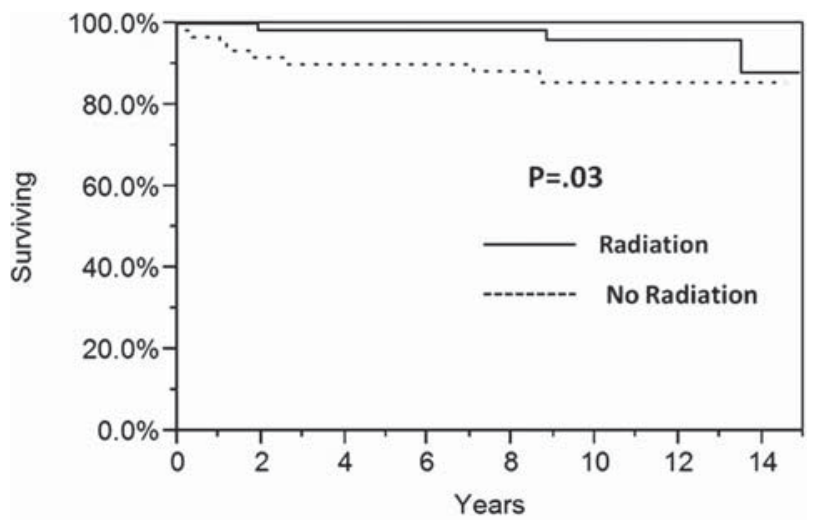

One limitation of the SEER database is a lack of randomization with regards to treatment. Other limitations include a lack of treatment details in the no RT group such as chemotherapeutic agents and doses.

In a highly curable disease such as stage IIA and IIB testicular seminoma, prevention of long-term complications of treatment is a priority. Retroperitoneal RT increases the relative risk (RR) of second non-germ-cell malignancies, including gastric (RR 4.1), pancreatic (RR 3.8), and colon (RR 1.9) cancers (10). Also, several groups have reported that retroperitoneal RT results in a twofold or greater risk of cardiovascular disease beyond 15 years, particularly when prophylactic mediastinal/ supraclavicular RT is added (11-13). Late effects are less well-defined for chemotherapy than they are for RT (10). The deleterious effects of 3-4 cycles of cisplatin-based chemotherapy on fertility are transitory, reversible, and dose-dependent (14). Huyghe et al. (14) suggested that RT has a more deleterious effect on fertility than chemotherapy in testicular cancer patients. However, RT in that study was antiquated by today's standards. Fertility can be preserved when the RT dose to the remaining testis is reduced to less than 2 Gy (15, 16). The cumulative incidence of spermatogenesis as a function of time appears to be similar after modern RT and cisplatin-based chemotherapy (16-18). A low but increased risk of development of acute myeloid leukemia is associated with chemotherapy, especially when etoposide is administered in high cumulative doses (19). Travis et al. (10) observed significantly increased risks of solid cancers among testicular cancer patients treated with $\mathrm{RT}$ alone $(\mathrm{RR}=2.0,95 \% \mathrm{CI}=1.9$ to 2.2 ), chemotherapy alone $(\mathrm{RR}=1.8,95 \% \mathrm{CI}=1.3$ to 2.5), and both ( $R R=2.9,95 \% \mathrm{CI}=1.9$ to 4.2$)$. Huddart et al. (12) observed an increased incidence of cardiovascular events in germ cell tumor patients treated with cisplatin-based chemotherapy. van den Belt-Dusebout et al. (20) reported that retroperitoneal RT strongly increases the risk of second malignancies but not of cardiovascular disease, whereas chemotherapy increases the risks of both second malignancies and cardiovascular disease. In addition, cisplatin-based chemotherapy has been associated with nephrotoxicity, ototoxicity, and neuropathy (21), especially when a large number of cycles of cisplatin is given. Fossa et al. (22) observed that men treated with chemotherapy (with or without RT) in 1975 or later had higher mortality from all non-cancer causes (standardized mortality ratio $(\mathrm{SMR})=1.34,95 \% \mathrm{CI}=1.15$ to 1.55), all circulatory diseases ( $\mathrm{SMR}=1.58,95 \% \mathrm{CI}$ $=1.25$ to 2.01), all infections $(\mathrm{SMR}=2.48,95 \% \mathrm{CI}$ $=1.70$ to 3.50 ), and all respiratory diseases (SMR $=2.53,95 \% \mathrm{CI}=1.26$ to 4.53 ). Active surveillance is not a management option post-orchiectomy for stage IIA and IIB disease; however, it is the preferred approach for stage IA and IB disease (23).

This report is the largest study of stage IIA and stage IIB testicular seminoma in the litera- 
ture. The 5-year OS and CSS rates of 96-98\% for RT are comparable with other reports $(5,8)$. Based on a median follow-up of 10 years in this study, RT was associated with improved OS in stage IIA (Figure-1) and IIB (Figure-2) disease. Patients who underwent RT had similar known characteristics such as age to those who did not undergo RT (Table-1). However, this study was not randomized. As a result, the improved OS in patients who received RT may be due to selection bias. Also, patients in the RT group could have received a single cycle of neoadjuvant carboplatin chemotherapy prior to RT, which reduces the risk of relapse (21). In addition, stage IIA and stage IIB testicular seminoma patients in the no RT group may have been treated with 4 cycles of single-agent carboplatin chemotherapy, which results in worse OS and progression-free survival than cisplatin-based chemotherapy $(24,25)$. In this report, no patients died of acute myeloid leukemia or infection in the RT group, whereas 2 patients died of these causes in the no RT group based on a median follow up of 10 years (Table-2). Most second malignancies and major cardiac events occur more than 15 years after RT $(8,13)$. As a result, longer follow-up is necessary to assess late toxicity and OS. Only 7 of $22(32 \%)$ deaths in this study were due to testicular seminoma (Table-2). Consequently, statistical power was limited for the assessment of CSS.

Chung et al. (5) reported 5-year relapse-free survival rates of 92\% and 90\%, respectively, for stage IIA and stage IIB testicular seminoma patients who underwent RT. Similarly, Classen et al. (6) reported 6-year relapse-free survival rates of 95\% and $89 \%$, respectively, for stage IIA and stage IIB patients who were treated with RT.

Modified dog-leg RT to 30 Gy in 15 fractions remains the preferred approach by most investigators for stage IIA testicular seminoma in the absence of a horseshoe kidney, inflammatory bowel disease, or a history of RT $(3,4,26,27)$. If one of these 3 contraindications to RT is present, then cisplatin-based combination chemotherapy is recommended $(3,4$, 26, 27). Prophylactic mediastinal/supraclavicular RT is no longer given for stage II testicular seminoma due to its late toxicity $(13,28)$.

In most studies, more than $80 \%$ of stage IIA patients received RT $(5,7,29)$. Similarly, 82\% of stage IIA patients in this report received RT. Nevertheless, cisplatin-based chemotherapy for good-risk testicular seminoma patients as defined by the IGCCCG (9) has gained in popularity over the past decade (30). One advantage of cisplatin-based chemotherapy is that it can eradicate carcinoma in situ in the remaining testis and prevent or postpone the development of an invasive cancer in some patients (17).

The Spanish Germ Cell Cancer Group conducted the first study of cisplatin-based chemotherapy as frontline therapy in stage IIA testicular seminoma patients (30). None of the 19 stage IIA patients relapsed. Also, in the Swedish and Norwegian Testicular Cancer Project (SWENOTECA) study (29), none of the 6 stage IIA patients who received cisplatin-based chemotherapy relapsed. Based on the impressive progression-free survival in these two studies, the European Society for Medical Oncology (31) recommends cisplatin-based chemotherapy or modified dog-leg RT to 30 Gy in 15 fractions, with no preference for one treatment option over another, for stage IIA testicular seminoma.

Cisplatin-based chemotherapy used to be reserved for stage IIB patients with high-volume disease, e.g., multiple lymph nodes measuring 3.1$5.0 \mathrm{~cm}(3,4)$. The Spanish Germ Cell Cancer Group conducted a study that included 54 patients with low-volume, e.g., a solitary retroperitoneal node measuring 2.1-3.0 cm, or high-volume stage IIB disease. Patients were treated with three cycles of cisplatin, etoposide, and bleomycin (PEB) or four cycles of cisplatin and etoposide (PE) (30). Median follow up was 72 months. The 5-year progression-free survival rate for stage IIB patients was $87 \%$. The SWENOTECA study included 67 stage IIB patients with low-volume or high-volume disease who were treated with cisplatin-based chemotherapy (29). None of them relapsed based on a median follow-up of 5.2 years. Based on the excellent progression-free survival in the SWENOTECA study, version 1.2014 of the National Comprehensive Cancer Network Clinical Practice Guidelines (32) and the European Society for Medical Oncology (31) recommend three cycles of PEB chemotherapy for all stage IIB patients, regardless of tumor burden. If there is a contraindication to bleomycin 
such as a reduction in lung capacity, emphysema, current or a history of heavy smoking, or poor renal function, then four cycles of PE may be used (31). Modified dog-leg RT to 36 Gy in 18 fractions also constitutes a treatment option for stage IIB patients in whom chemotherapy would be unsuitable (31) or who have a solitary retroperitoneal node measuring 2.1-3.0 cm (32).

One treatment that has been investigated for stage IIA and IIB testicular seminoma is a single course of neoadjuvant carboplatin chemotherapy followed by para-aortic RT to 30-35 Gy. In a series involving 51 patients, there have been no relapses after a median follow up of 55 months (21). Eight per cent of patients experienced grade 3 hematological toxicity and 2\% developed grade 3 nausea. These results are promising; however, additional investigation is needed $(3,30)$.

\section{CONCLUSIONS}

Stage IIA testicular seminoma patients in the U.S. underwent RT more often than stage IIB patients between 1988 and 2003. There was no significant change in RT utilization for stage IIA or IIB disease during this time period. Cisplatin-based chemotherapy has produced excellent progression-free survival and, as a result, may eventually become the most popular treatment approach for both stage IIA and IIB testicular seminoma.

\section{REFERENCES}

1. Hoffman KE, Chen MH, Punglia RS, Beard CJ, D’Amico AV. Influence of year of diagnosis, patient age, and sociodemographic status on recommending adjuvant radiation treatment for stage I testicular seminoma. J Clin Oncol. 2008;26:3937-42.

2. Morton GC, Thomas GM. Testis. In: Perez CA, Brady LW, Halperin EC, Schmidt-Ullrich RK, editors. Principles and Practice of Radiation Oncology. 4th ed. Philadelphia: Lippincott, Williams \& Wilkins; 2004; pp. 1763-84.

3. Chung PW, Bedard P. Stage II seminomas and nonseminomas. Hematol Oncol Clin North Am. 2011;25:529-41.

4. Warde P, Huddart R, Bolton D, Heidenreich A, Gilligan T, Fossa S. Management of localized seminoma, stage I-II: SIU/ICUD Consensus Meeting on Germ Cell Tumors (GCT), Shanghai 2009. Urology. 2011;78(4 Suppl):S435-43.
5. Chung PW, Gospodarowicz MK, Panzarella T, Jewett MA, Sturgeon JF, Tew-George, et al. Stage II testicular seminoma: patterns of recurrence and outcome of treatment. Eur Urol. 2004:45:754-59; discussion 759-60.

6. Classen J, Schmidberger H, Meisner C, Souchon R, SautterBihl ML, Sauer R, et al. Radiotherapy for stages IIA/B testicular seminoma: final report of a prospective multicenter clinical trial. J Clin Oncol. 2003;21:1101-6.

7. Detti B, Livi L, Scoccianti S, Gacci M, Lapini A, Cai T, et al. Management of Stage II testicular seminoma over a period of 40 years. Urol Oncol. 2009;27:534-8.

8. Hallemeier CL, Pisansky TM, Davis BJ, Choo R. Long-term outcomes of radiotherapy for stage II testicular seminoma-the Mayo Clinic experience. Urol Oncol. 2013;31:1832-8.

9. International Germ Cell Consensus Classification: a prognostic factor-based staging system for metastatic germ cell cancers. International Germ Cell Cancer Collaborative Group. J Clin Oncol. 1997;15:594-603.

10. Travis LB, Fosså SD, Schonfeld SJ, McMaster ML, Lynch CF, Storm H, et al. Second cancers among 40,576 testicular cancer patients: focus on long-term survivors. J Natl Cancer Inst. 2005;97:1354-65.

11. Haugnes HS, Wethal T, Aass N, Dahl 0, Klepp 0, Langberg $\mathrm{CW}$, et al. Cardiovascular risk factors and morbidity in longterm survivors of testicular cancer: a 20-year follow-up study. J Clin Oncol. 2010;28:4649-57.

12. Huddart RA, Norman A, Shahidi M, Horwich A, Coward $D$, Nicholls J, et al. Cardiovascular disease as a long-term complication of treatment for testicular cancer. J Clin Oncol. 2003 Apr 15;21(8):1513-23.

13. Zagars GK, Ballo MT, Lee AK, Strom SS. Mortality after cure of testicular seminoma. J Clin Oncol. 2004;22:640-7.

14. Huyghe E, Matsuda T, Daudin M, Chevreau C, Bachaud JM, Plante $\mathrm{P}$, et al. Fertility after testicular cancer treatments: results of a large multicenter study. Cancer. 2004;100:732-7.

15. Malas S, Levin V, Sur RK, Donde B, Krawitz HE, Pacella $\mathrm{JA}$. Fertility in patients treated with radiotherapy following orchidectomy for testicular seminoma. Clin Oncol (R Coll Radiol). 1994;6:377-80.

16. Nalesnik JG, Sabanegh ES Jr, Eng TY, Buchholz TA. Fertility in men after treatment for stage 1 and $2 A$ seminoma. Am J Clin Oncol. 2004;27:584-8.

17. Christensen TB, Daugaard G, Geertsen PF, von der Maase $\mathrm{H}$. Effect of chemotherapy on carcinoma in situ of the testis. Ann Oncol. 1998;9:657-60.

18. Malas S, Levin V, Sur RK, Donde B, Krawitz HE, Pacella $J A$. Fertility in patients treated with radiotherapy following orchidectomy for testicular seminoma. Clin Oncol (R Coll Radiol). 1994;6:377-80.

19. Travis LB, Andersson M, Gospodarowicz M, van Leeuwen FE, Bergfeldt K, Lynch CF, et al. Treatment-associated leukemia following testicular cancer. J Natl Cancer Inst. 2000;92:1165-71. 
20. van den Belt-Dusebout AW, de Wit R, Gietema JA, Horenblas S, Louwman MW, Ribot JG, et al. Treatment-specific risks of second malignancies and cardiovascular disease in 5-year survivors of testicular cancer. J Clin Oncol. 2007;25:4370-8.

21. Horwich A, Dearnaley DP, Sohaib A, Pennert K, Huddart RA. Neoadjuvant carboplatin before radiotherapy in stage IIA and IIB seminoma. Ann Oncol. 2013;24:2104-7.

22. Fosså SD, Gilbert E, Dores GM, Chen J, McGlynn KA, Schonfeld $S$, et al. Noncancer causes of death in survivors of testicular cancer. J Natl Cancer Inst. 2007;99:533-44.

23. Motzer RJ, Agarwal N, Beard C, Bhayani S, Bolger GB, Buyyounouski MK, et al. Testicular cancer. J Natl Compr Canc Netw. 2012;10:502-35.

24. Bokemeyer C, Kollmannsberger C, Stenning S, Hartmann JT, Horwich A, Clemm C, et al. Metastatic seminoma treated with either single agent carboplatin or cisplatinbased combination chemotherapy: a pooled analysis of two randomised trials. Br J Cancer. 2004;91:683-7.

25. Krege S, Boergermann C, Baschek R, Hinke A, Pottek T, Kliesch S, et al. Testicular Cancer Study Group (GTCSG). Single agent carboplatin for CS IIA/B testicular seminoma. A phase II study of the German Testicular Cancer Study Group (GTCSG). Ann Oncol. 2006;17:276-80.

26. Schmoll HJ, Jordan K, Huddart R, Pes MP, Horwich A, Fizazi K, et al. Testicular seminoma: ESMO Clinical Practice Guidelines for diagnosis, treatment and follow-up. Ann Oncol. 2010;21(Suppl 5):v140-6.
27. Wilder RB, Buyyounouski MK, Efstathiou JA, Beard CJ. Radiotherapy treatment planning for testicular seminoma. Int J Radiat Oncol Biol Phys. 2012;83:e445-52.

28. Chung PW, Warde PR, Panzarella T, Bayley AJ, Catton CN, Milosevic MF, et al. Appropriate radiation volume for stage IIA/B testicular seminoma. Int J Radiat Oncol Biol Phys. 2003;56:746-8.

29. Tandstad T, Smaaland R, Solberg A, Bremnes RM, Langberg CW, Laurell A, et al. Management of seminomatous testicular cancer: a binational prospective population-based study from the Swedish norwegian testicular cancer study group. J Clin Oncol. 2011;29:719-25.

30. Garcia-del-Muro X, Maroto P, Gumà J, Sastre J, López Brea M, Arranz JA, et al. Chemotherapy as an alternative to radiotherapy in the treatment of stage IIA and IIB testicular seminoma: a Spanish Germ Cell Cancer Group Study. J Clin Oncol. 2008;26:5416-21.

31. Oldenburg J, Fosså SD, Nuver J, Heidenreich A, Schmoll HJ, Bokemeyer C. Testicular seminoma and non-seminoma: ESMO Clinical Practice Guidelines for diagnosis, treatment and follow-up. Ann Oncol. 2013;24(Suppl 6):vi125-32.

32. NCCN Clinical Practice Guidelines in Oncology (NCCN Guidelines): Testicular Cancer, Version 1.2014. Retrieved on April 22, 2014. Available at: http://www.cus.cz/wpcontent/uploads/2012/10/NCCN-C62-2014.pdf.

Correspondence address: Richard B. Wilder, MD Department of Radiation Oncology H. Lee Moffitt Cancer Center and Research Institute 12902 Magnolia Dr. Tampa, FL, 33612, USA Fax: + 1813 745-7231 E-mail: richard.wilder@moffitt.org 